\title{
Lower Jugular Lymph Node Group (Level IV)
}

National Cancer Institute

\section{Source}

National Cancer Institute. Lower Jugular Lymph Node Group (Level IV). NCI Thesaurus.

Code C132512.

Lymph nodes located around the lower third of the internal jugular vein, extending from the inferior border of the cricoid cartilage (above) to the clavicle below. The anterior (medial) boundary is the lateral border of the sternohyoid muscle and the posterior (lateral) boundary is the posterior border of the sternocleidomastoid muscle. These nodes are at greatest risk for harboring metastases from cancers arising from the hypopharynx, thyroid, cervical esophagus, and larynx. (AJCC 8th ed.) 